\title{
Prevalence of Anxiety and Depression in India among Medicos and Non-Medicos during Covid 19: A Survey
}

\author{
Meghna Gupta ${ }^{1}$, Vitull K Gupta ${ }^{2}{ }^{*}$, Navjot Kaur ${ }^{3}$, Parneet K Hari ${ }^{4}$, Kashish Goyal ${ }^{5}$ \\ ${ }^{1}$ Junior Resident, Department of psychiatry, Maharishi Markandeshwar Medical College and Hospital, Kumarhatti, Solan, \\ Himachal Pradesh, India \\ ${ }^{2}$ Professor, Department of Medicine, Kishori Ram Hospital and Diabetes Care Centre, Bathinda, Punjab, India \\ ${ }^{3}$ Associate Professor, Department of Pathology, Government Medical College, Amritsar, Punjab, India \\ ${ }^{4}$ MBBS Intern, Government Medical College, Patiala, Punjab, India \\ ${ }^{5}$ MBBS Intern Dayanand Medical College, Ludhiana, Punjab, India
}

\begin{abstract}
*Address for Correspondence: Dr. Vitull K Gupta, Professor, Department of Medicine, Kishori Ram Hospital and Diabetes Care Centre, Bathinda-151001, Punjab, India

E-mail: vitullgupta2000@yahoo.com
\end{abstract}

Received: 23 Apr 2021/ Revised: 12 June 2021/ Accepted: 28 Aug 2021

\begin{abstract}
Background: Emerging evidence suggests a significant risk of mental health issues been associated with disease pandemics in past and during the present COVID-19 pandemic. Generalised anxiety disorders and depression are considered one of the most common mental disorders and there is a paucity of studies documenting their prevalence during the COVID-19 pandemic.

Methods: We conducted this survey using completely voluntary anonymous Generalized Anxiety Disorder Questionnaire-7 (GAD7) and Patient Health Questionnaire-9 (PHQ-9) by distributing hard copies and e-copies after ethical approval. The anonymous survey questionnaire included socio-demographic characteristics like age, gender, medico or non-medico and residence in Punjab or outside Punjab.

Results: A total of 4333 subjects completed the survey. The prevalence of anxiety in the study population was $80.5 \%$ including $79.3 \%$ among medicos and $81.9 \%$ among non-medicos. The prevalence of depression in the study population was $73.3 \%$ including $74.7 \%$ among medicos and $71.7 \%$ among non-medicos. Most of the study population, medicos and non-medicos had mild anxiety and minimal depression as compared to another level of severity of anxiety and depression.

Conclusion: Our survey shows the high prevalence of anxiety and depression as compared to other studies documented in the literature, necessitating an increased focus on mental health issues and their psychological impacts to contain and curb grave adverse effects of anxiety and depression along with the need for early diagnosis and appropriate management of mental health disorders.
\end{abstract}

Key-words: Anxiety, COVID-19, Depression, Minimal depression, Prevalence, SARS-CoV-2

\section{INTRODUCTION}

In December 2019 origin of a coronavirus strain called Severe Acute Respiratory Syndrome Coronavirus 2 (SARS-CoV-2 or COVID-19) was reported at Wuhan in China in a Hunan seafood market ${ }^{[1]}$ and on 20 January 2020, the human-to-human transmission was reported and confirmed. ${ }^{[2]}$

\section{How to cite this article}

Gupta M, Gupta VK, Kaur N, Hari PK, Goyal K. Prevalence of Anxiety and Depression in India among Medicos and Non-Medicos during Covid 19: A Survey. SSR Inst. Int. J. Life Sci., 2021; 7(5): 2890-2900.

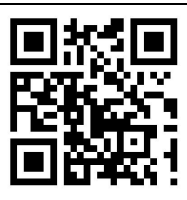

Access this article online https://iijls.com/
On 30 January 2020, World Health Organisation (WHO) declared COVID-19 as a Public Health Emergency of International Concern and the first case was reported in India. On March 11, 2020, WHO declared the COVID-19 outbreak as a global pandemic ${ }^{\text {[3] }}$ and on 23.3.2020 a complete lockdown was enforced by the government of India. Evidence suggests that severe psychological problems have been associated with disease pandemics in past and a systematic review has shown that loneliness and social isolation was associated with worse mental health outcomes. ${ }^{[4]}$ Moreover, the COVID-19 pandemic forcing complete lockdown caused enormous human suffering and adversely affecting the economy causing universal psychosocial impact. ${ }^{[5]}$ Globally, 
emerging evidence shows that the COVID pandemic presents a significant risk of mental health issues and is recognized as an important mental health care challenge. ${ }^{[6]}$

The psychological reaction of the population to any pandemic or disease outbreak plays an important role in managing the disease pandemic. Despite these facts, sufficient measures or resources were not provided for attenuating pandemics' effects on the psychological health and wellbeing of the population. ${ }^{[7]}$ In pre-COVID19 times, some population-based studies and the National Mental Health Survey (2015-16) have documented the prevalence of anxiety and depression in India. ${ }^{[8]}$ Generalized Anxiety Disorder Questionnaire-7 (GAD-7) ${ }^{[9]}$ and Patient Health Questionnaire-9 (PHQ-9) ${ }^{[10]}$ are effective screening tools found to be useful for a diagnosis of GAD and depression, especially in epidemiological studies and surveys. Preliminary evidence presented by a review of 28 research articles showed $16-28 \%$ symptoms of anxiety and depression during the COVID-19 pandemic. ${ }^{[11]}$ A systematic review and meta-regression analysis of 29 studies using different assessment scales showed $25.8 \%$ (95\% Cl 20.5$31.9 \%)$ prevalence of anxiety, $24.3 \%(95 \% \mathrm{Cl} 18.2-31.6 \%)$ prevalence of depression among hospital staff engaged in COVID-19 care. ${ }^{[12]}$ There is a paucity of quantifiable information, which was important for policymakers to make the appropriate policies to address increasing mental health problems. ${ }^{[13]}$ So we conducted this survey to evaluate the prevalence of anxiety and depression among the general population including medicos and non-medicos in India.

\section{MATERIALS AND METHODS}

We conducted this survey between $1^{\text {st }}$ October 2020 to $20^{\text {th }}$ February 2021 to assess the prevalence of anxiety and depression in the Indian population during COVID 19 pandemic using hard copies and e-copies of the completely voluntary anonymous questionnaire.

Inclusion criteria: Willingness to participate, Age more than 18 years, Ability to read and understand English.

Exclusion criteria: Not consenting to participate, Age less than 18 years, Unable to read and understand English. The anonymous survey questionnaire included sociodemographic characteristics like age, gender, medico or non-medico and residence in Punjab or outside Punjab.
Anxiety and depression symptoms were assessed by using GAD-7 ${ }^{[9]}$ and PHQ-9 scales. ${ }^{[10]}$ GAD-7 contained seven questions and PHQ-9 contained nine questions to access severity on a 4-point scale of 0-3 ( 0- not at all, 1several days, 2- more than half the day, 3- nearly every day) rating the symptoms in past two weeks. GAD-7 score of 0-no anxiety, 1-5 mild anxiety, 6-10 moderate anxiety and $\geq 11$ severe anxiety. ${ }^{[9]}$ PHQ-9 score of 0 - no depression, 1-4- minimal depression, 5-9- mild depression, 10-14- moderate depression, 15-19moderately severe depression and a score of 20-27 indicated severe depression. ${ }^{[10]}$ The GAD-7 and PHQ-9 have been documented as a valid and reliable screening tools used in research studies related to Middle East respiratory syndrome (MERS), Ebola outbreak and covid19 in China ${ }^{[9,14]}$.

Ethical Approval: Ethical approval was obtained from the Institutional Ethical Committee.

Statistical Analysis- Data was represented as frequency and percentage. Association of levels of scores with socio-demographic variables represented as frequency and percentage was calculated using Chi-Square Test. $\mathrm{P}$ value less than 0.05 was taken as statistically significant whereas $P$ value more than 0.001 was taken as highly significant. All the analysis was done using 'IBM SPSS Statistics for Windows, version 23.0 (IBM Corp., Armonk, N.Y., USA)'.

\section{RESULTS}

Socio-demographic characteristics- Table 1 shows the socio-demographic characteristics of the study population. A total of 4333 subjects participated in the survey, out of which 2246 (51.8\%) were medicos and 2087 (48.2\%) were non-medicos. Study population included 2741(63.3\%) males and 1592 (36.7\%) females. Medicos group included 1513 (55.2\%) males and 733 (46\%) females, whereas non-medicos group included 1228 (44.8\%) males and 859 (54\%) females. 2335 (53.9\%) study subjects belonged to Punjab region including 634 (27.2\%) medicos and 1701 (72.8\%) non-medicos. 1998 (46.1\%) study subjects were from out of Punjab region including 1612 (80.7\%) medicos and $386(19.3 \%)$ nonmedicos. 
Table 1: Socio-demographic characteristics of the study population, medicos and non-medicos according to the age groups [N (\%)]

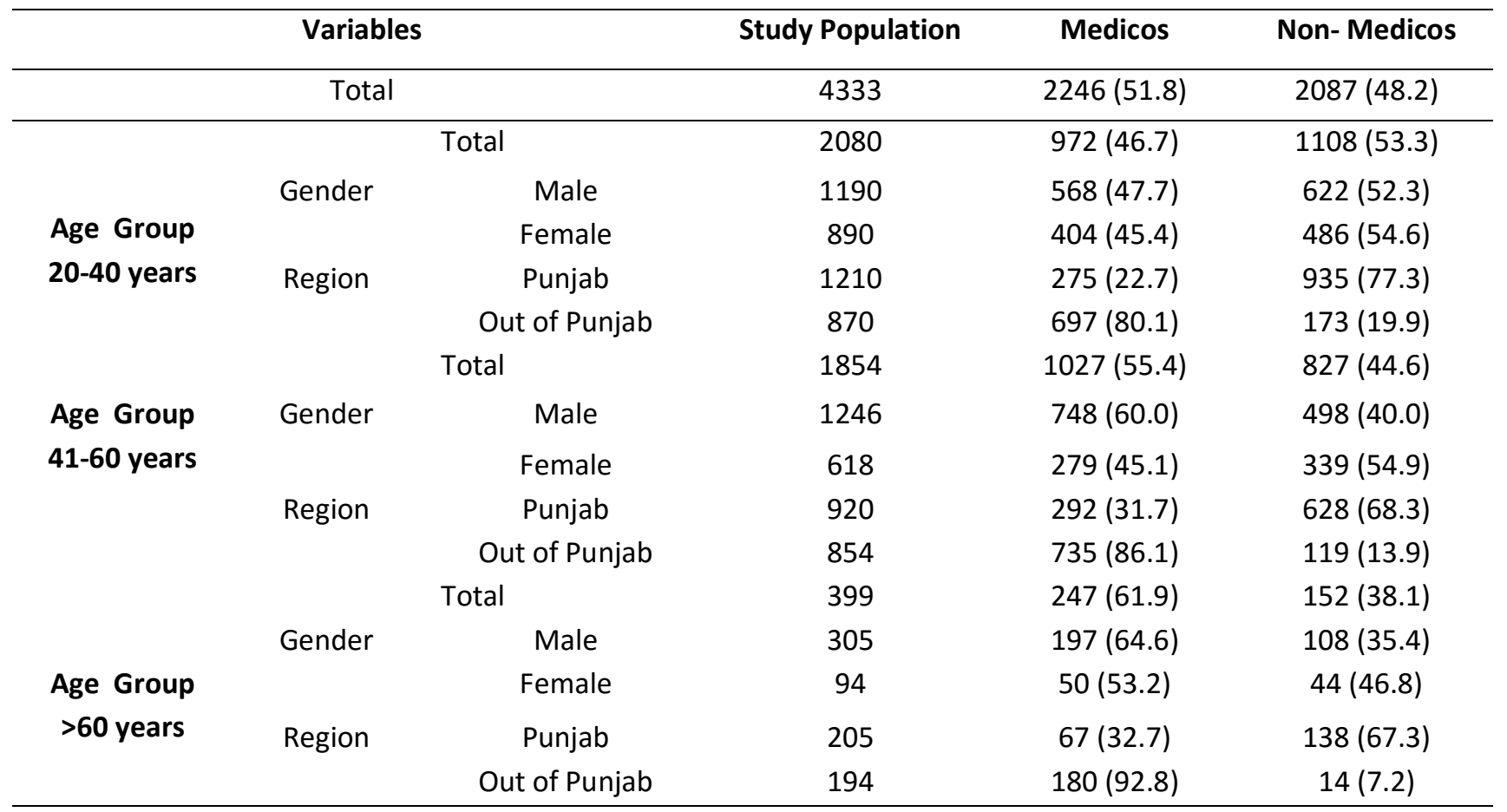

Prevalence of anxiety and depression- Table 2 shows the prevalence of anxiety (score $\geq 1$ on GAD-7) in the study population was $80.5 \%(95 \% \mathrm{Cl} 72.50-88.50)$ and the difference of prevalence of anxiety among sociodemographic variables was observed to be statistically highly significant in all sub-groups except region group where it was statistically significant. The prevalence of depression (score $\geq 1$ on PHQ-9) in the study population was $73.3 \%(95 \% \mathrm{Cl} 64.30-82.30)$ and the difference in the prevalence of depression among socio-demographic variables was statistically highly significant except the subgroup of the region where it was statistically nonsignificant.

Table 2: Prevalence of anxiety and depression according to various socio-demographic variables in study population $\mathrm{N}$ (\%)

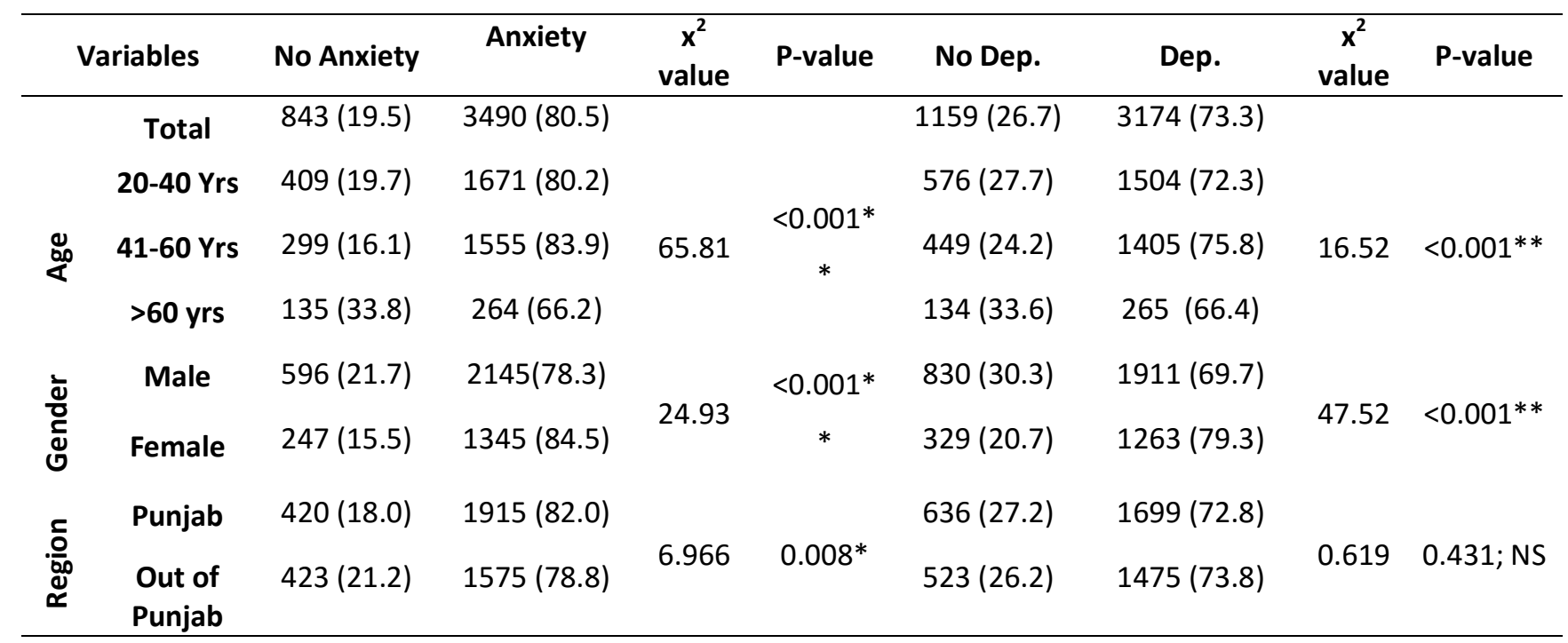

GAD-7 Scale: Score 0 No Anxiety, $\geq 1$ Anxiety. PHQ-9 Scale: Score 0 No Depression (Dep), $\geq 1$ Depression (Dep). P Value: ** Statistically highly significant $(p<0.001)$, * Statistically significant $(p<0.05)$, 
Table 3: Confidence Interval (Cl) for anxiety and depression in the study population and according to variables

\begin{tabular}{|c|c|c|c|c|c|c|c|c|c|}
\hline & \multirow{3}{*}{ Variables } & \multirow{2}{*}{\multicolumn{2}{|c|}{$\begin{array}{c}\text { No Anxiety } \\
95 \% \mathrm{Cl}\end{array}$}} & \multirow{2}{*}{\multicolumn{2}{|c|}{$\begin{array}{c}\text { Anxiety } \\
95 \% \mathrm{Cl}\end{array}$}} & \multirow{2}{*}{\multicolumn{2}{|c|}{$\begin{array}{c}\text { No Depression. } \\
95 \% \mathrm{Cl}\end{array}$}} & \multirow{2}{*}{\multicolumn{2}{|c|}{$\begin{array}{c}\text { Depression. } \\
95 \% \mathrm{Cl}\end{array}$}} \\
\hline & & & & & & & & & \\
\hline & & Lower & Upper & Lower & Upper & Lower & Upper & Lower & Upper \\
\hline \multirow{4}{*}{ Age } & Total & 11.50 & 27.50 & 72.50 & 88.50 & 17.70 & 35.70 & 64.30 & 82.30 \\
\hline & $20-40$ Yrs & 11.70 & 27.70 & 72.30 & 88.30 & 18.70 & 36.70 & 63.30 & 81.30 \\
\hline & $41-60$ Yrs & 9.10 & 23.10 & 76.90 & 90.90 & 16.20 & 32.20 & 67.80 & 83.80 \\
\hline & $>60 \mathrm{yrs}$ & 24.80 & 42.80 & 57.20 & 75.20 & 24.60 & 42.60 & 57.40 & 75.40 \\
\hline \multirow{2}{*}{ Gender } & Male & 13.70 & 29.70 & 70.30 & 86.30 & 21.30 & 39.30 & 60.70 & 78.70 \\
\hline & Female & 8.50 & 22.50 & 77.50 & 91.50 & 12.70 & 28.70 & 71.30 & 87.30 \\
\hline \multirow{2}{*}{ Region } & Punjab & 10.00 & 26.00 & 74.00 & 90.00 & 18.20 & 36.20 & 63.80 & 81.80 \\
\hline & Out of Punjab & 13.20 & 29.20 & 70.80 & 86.80 & 17.20 & 35.20 & 64.80 & 82.80 \\
\hline
\end{tabular}

GAD-7 Scale: Score 0 No Anxiety, $\geq 1$ Anxiety. PHQ-9 Scale: Score 0 No Depression, $\geq 1$ Depression

Table 4 shows the prevalence of anxiety among medicos was $79.3 \%$ and $81.9 \%$ among non-medicos and the difference was statistically significant. Prevalence of anxiety between medicos and non-medicos shows the statistically significant difference in sub-groups of 41-60 years age group, $>60$ years age group and females whereas in subgroups of 20-40 years age group, males, region both Punjab and outside Punjab, the difference was statistically not-significant. The prevalence of depression among medicos was $74.7 \%$ and $71.7 \%$ among non-medicos and the difference was statistically significant, whereas the difference was statistically highly significant in sub-groups of 20-40 years age group and males, statistically significant difference in females, those residing in Punjab and the difference was statistically non-significant in 41-60 years age group, $>60$ years age group and those residing outside Punjab.

Table 4: Prevalence of anxiety and depression according to various socio-demographic variables among medicos and non-medicos $\mathrm{N}(\%)$

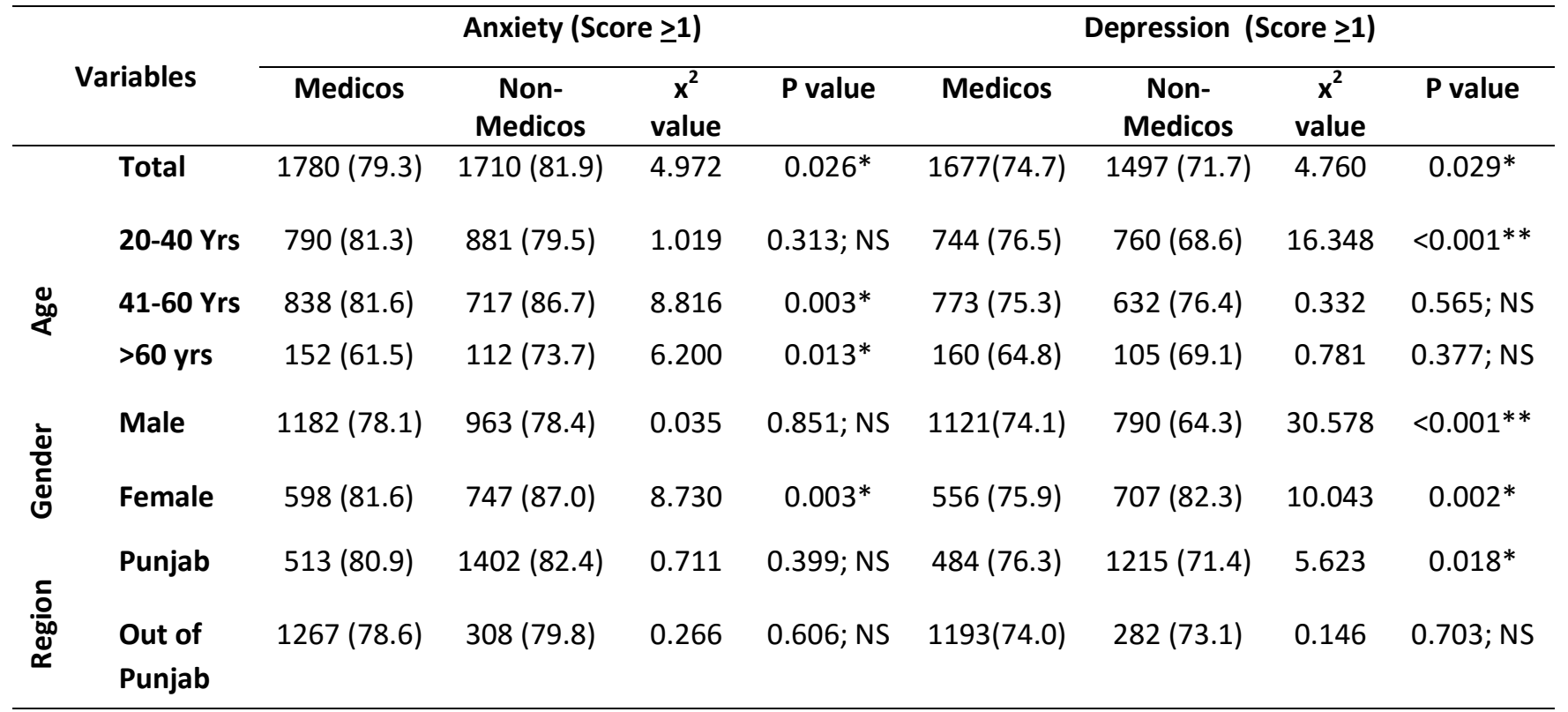


Prevalence of anxiety and depression according to severity score: Table 5 shows that $9.5 \%$ of subjects had no anxiety, $42.1 \%$ mild anxiety, $31.6 \%$ moderate and $6.9 \%$ subjects had severe anxiety. The comparison among different sub-groups of socio-demographic variables showed a statistically highly significant difference in all sub-groups except the sub-group of the region where it was statistically significant.

Table 5: Prevalence of anxiety (GAD-7 scale) according to severity among socio-demographic variables in the study population $\mathrm{N}(\%)$

\begin{tabular}{|c|c|c|c|c|c|c|c|}
\hline \multirow{2}{*}{\multicolumn{2}{|c|}{ Variables }} & \multicolumn{4}{|c|}{ Study Population } & \multirow{2}{*}{$x^{2}$ value } & \multirow{2}{*}{ P-value } \\
\hline & & No anxiety & Mild anxiety & Moderate anxiety & Severe anxiety & & \\
\hline \multirow{4}{*}{$\begin{array}{c}\text { Age } \\
\text { Groups }\end{array}$} & Total & 843 (19.5\%) & $1823(42.1 \%)$ & $1369(31.6 \%)$ & $298(6.9 \%)$ & \multirow{4}{*}{90.920} & \multirow{4}{*}{$<0.001^{* *}$} \\
\hline & $20-40$ Yrs & 409 (19.7\%) & 897 (43.1\%) & $616(29.6 \%)$ & $158(7.6 \%)$ & & \\
\hline & $41-60$ Yrs & 299 (16.1\%) & $800(43.1 \%)$ & $653(35.2 \%)$ & $102(5.5 \%)$ & & \\
\hline & $>60 \mathrm{yrs}$ & 135 (33.8\%) & $126(31.6 \%)$ & $100(25.1 \%)$ & $38(9.5 \%)$ & & \\
\hline \multirow{2}{*}{ Gender } & Male & 596 (21.7\%) & 1345 (49.1\%) & $662(24.2 \%)$ & $138(5 \%)$ & \multirow{2}{*}{274.545} & \multirow{2}{*}{$<0.001 * *$} \\
\hline & Female & 247 (15.5\%) & $478(30 \%)$ & 707 (44.4\%) & $160(10.1 \%)$ & & \\
\hline \multirow[b]{2}{*}{ Region } & Punjab & $420(18 \%)$ & 1022 (43.8\%) & 735 (31.5\%) & $158(6.8 \%)$ & \multirow[b]{2}{*}{9.186} & \multirow[b]{2}{*}{$0.027^{*}$} \\
\hline & $\begin{array}{l}\text { Out of } \\
\text { Punjab }\end{array}$ & $423(21.2 \%)$ & 801 (40.1\%) & $634(31.7 \%)$ & $140(7 \%)$ & & \\
\hline
\end{tabular}

GAD-7 scale: Score 0: no Anxiety, 1-5 mild anxiety, 6-10 moderate anxiety and $\geq 11$ severe anxiety

P Value: ** Statistically highly significant $(p<0.001), *$ Statistically significant $(p<0.05)$, Statistically non-significant $(p>0.05)(N S)$

Table 6 shows the prevalence of anxiety according to severity score in medicos and non-medicos groups and various socio-demographic sub-groups. The difference in severity score of anxiety among medicos and nonmedicos was statistically highly significant and in different sub-groups of socio-demographic variables, the difference was statistically highly significant in all subgroups and statistically not-significant in subgroup of the Punjab region.

Table 6: Prevalence of anxiety according to severity among the socio-demographic variables and in medicos and nonmedicos $\mathrm{N}(\%)$

\begin{tabular}{|c|c|c|c|c|c|c|c|c|c|}
\hline \multirow{2}{*}{\multicolumn{2}{|c|}{ Variables }} & \multicolumn{3}{|c|}{ Medicos } & \multicolumn{3}{|c|}{ Non-Medicos } & \multirow[b]{2}{*}{$x^{2}$ value } & \multirow[b]{2}{*}{ P value } \\
\hline & & $\begin{array}{l}\text { Mild } \\
\text { anxiety }\end{array}$ & $\begin{array}{c}\text { Moderate } \\
\text { anxiety }\end{array}$ & $\begin{array}{l}\begin{array}{l}\text { Severe } \\
\text { anxiety }\end{array} \\
\end{array}$ & $\begin{array}{l}\text { Mild } \\
\text { anxiety }\end{array}$ & $\begin{array}{c}\text { Moderate } \\
\text { anxiety }\end{array}$ & $\begin{array}{l}\text { Severe } \\
\text { anxiety }\end{array}$ & & \\
\hline \multirow{4}{*}{ 品 } & tal & $904(40.2)$ & $690(30.7)$ & $186(8.3)$ & $919(44.0)$ & $679(32.5)$ & $112(5.4)$ & 22.179 & $<0.001 * *$ \\
\hline & $20-40$ Yrs & $386(39.7)$ & $312(32.1)$ & $92(9.5)$ & $511(46.1)$ & $304(27.4)$ & $66(6.0)$ & 17.937 & $<0.001^{* *}$ \\
\hline & $41-60$ Yrs & $426(41.5)$ & $340(33.1)$ & $72(7.0)$ & $374(45.2)$ & $313(37.8)$ & $30(3.6)$ & 21.337 & $<0.001^{* *}$ \\
\hline & $>60 \mathrm{yrs}$ & $92(37.2)$ & $38(15.4)$ & $22(8.9)$ & $34(22.4)$ & $62(40.8)$ & $16(10.5)$ & 35.189 & $<0.001 * *$ \\
\hline \multirow{2}{*}{ 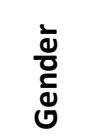 } & Male & $664(43.9)$ & $420(27.8)$ & $98(6.5)$ & $681(55.5)$ & $242(19.7)$ & $40(3.3)$ & 50.676 & $<0.001 * *$ \\
\hline & Female & $240(32.7)$ & $270(36.8)$ & $88(12.0)$ & $238(27.7)$ & 437 (50.9) & $72(8.4)$ & 33.434 & $<0.001 * *$ \\
\hline \multirow{2}{*}{ 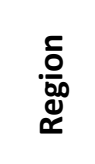 } & Punjab & $265(41.8)$ & $193(30.4)$ & $55(8.7)$ & $57(44.5)$ & $542(31.9)$ & $103(61)$ & 6.337 & 0.096 (NS) \\
\hline & $\begin{array}{l}\text { Out of } \\
\text { Punjab }\end{array}$ & $639(39.6)$ & $497(30.8)$ & $131(8.1)$ & $162(42)$ & 137 (35.5 & $9(2.3)$ & 17.689 & $0.001 *$ \\
\hline
\end{tabular}


The overall prevalence of depression according to severity score in the study population as well as among various socio-demographic sub-groups is expressed in Table 7. The difference severity score of depression among all the sub-groups of socio-demographic variables was statistically highly significant except in sub-groups of the region where the difference was statistically nonsignificant.

Table 7: Prevalence of Depression According to Severity among the Socio-demographic Variables in study population N (\%)

\begin{tabular}{|c|c|c|c|c|c|c|c|c|}
\hline & & & & tudy Populat & & & & \\
\hline & Variables & Minimal & Mild & Moderate & Moderately & Severe & $x^{2}$ value & $P$ value \\
\hline & Total & $1681(38.8 \%)$ & $1218(28.1 \%)$ & $229(5.3 \%)$ & 45 (1\%) & $1(0.02 \%)$ & & \\
\hline & $20-40$ Yrs & 767 (36.9\%) & 575 (27.6\%) & 132 (6.3\%) & 30 (1.4\%) & $0(0.0)$ & 43095 & $<0.001 * *$ \\
\hline 인 & 41-60 Yrs & 786 (42.4\%) & 527 (28.4\%) & 81 (4.4\%) & $10(0.5 \%)$ & $1(0.1 \%)$ & & \\
\hline 0 & $>60 \mathrm{yrs}$ & $128(32.1 \%)$ & $116(29.1 \%)$ & $16(4 \%)$ & $5(1.3 \%)$ & $0(0.0)$ & & \\
\hline & Male & 1174 42.8\%) & $610(22.3 \%)$ & 109 (4\%) & $17(0.6 \%)$ & $1(0.04 \%)$ & 101971 & 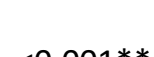 \\
\hline$\Phi$ & Female & 507 (31.8\%) & 608 (38.2\%) & 120 (7.5\%) & $28(1.8 \%)$ & $0(0.0)$ & & \\
\hline & Punjab & 908 (38.9\%) & 633 (27.1\%) & 132 (5.7\%) & $26(1.1 \%)$ & $0(0.0)$ & & \\
\hline$\frac{0}{90}$ & $\begin{array}{l}\text { Out of } \\
\text { Punjab }\end{array}$ & 773 (38.7\%) & 585 (29.3\%) & 97 (4.9\%) & $19(1 \%)$ & $1(0.1 \%)$ & .009 & $.415 ;$ NS \\
\hline
\end{tabular}

PHQ-9 Scale: Score 0 no Depression, 1-4: Minimal depression, 5-9: Mild depression, 10-14: Moderate depression, 15-19; Moderately severe depression, 20-27: Sever depression.

P Value: **Statistically highly significant $(p<0.001)$, *Statistical significant $(p<0.05)$, Statistical non-significant $(p>0.05)$ (NS)

The overall prevalence of depression according to severity score in medicos and non-medicos and among various socio-demographic sub-groups is expressed in Table 8. The difference in severity score of depression between medicos and non-medicos was statistically significant. Among different sub-groups of sociodemographic variables, a statistically highly significant difference was observed in subgroups of 20-40 years age, $>60$ years of age and males, whereas among females and Punjab region, the difference was statistically significant. Statistically, a non-significant difference was found in sub-groups of 41-60 years of age and out of the Punjab region

Table 8: Prevalence of depression according to severity among the socio-demographic variables in medicos and nonmedicos $\mathrm{N}$ (\%)

\begin{tabular}{|c|c|c|c|c|c|c|c|c|c|c|c|}
\hline \multirow{2}{*}{\multicolumn{2}{|c|}{ Variables }} & \multicolumn{4}{|c|}{ Medicos } & \multicolumn{4}{|c|}{ Non-Medicos } & \multirow{2}{*}{$\begin{array}{c}x^{2} \\
\text { value }\end{array}$} & \multirow[b]{2}{*}{ P-value } \\
\hline & & $\begin{array}{l}\text { Minimal } \\
\text { Dep }\end{array}$ & Mild Dep & $\begin{array}{l}\text { Mod } \\
\text { Dep }\end{array}$ & $\begin{array}{c}\text { Mod } \\
\text { severe } \\
\text { Dep }\end{array}$ & $\begin{array}{l}\text { Minimal } \\
\text { Dep }\end{array}$ & $\begin{array}{l}\text { Mild } \\
\text { Dep }\end{array}$ & $\begin{array}{l}\text { Mod } \\
\text { Dep }\end{array}$ & $\begin{array}{c}\text { Mod } \\
\text { severe } \\
\text { Dep }\end{array}$ & & \\
\hline \multirow[b]{3}{*}{ 总 } & otal & $895(39.8)$ & $621(27.6)$ & 130 & $30(1.3)$ & $786(37.7)$ & $597(28.6)$ & $99(4.7)$ & $15(.7)$ & 12.300 & $0.031^{*}$ \\
\hline & $20-40$ & $361(37.1)$ & 291(29.9) & $75(7.7)$ & $17(1.7)$ & $406(36.6)$ & $284(25.6)$ & $57(5.1)$ & $13(1.2)$ & 21.915 & $<0.001^{* *}$ \\
\hline & $\begin{array}{c}\text { Yrs } \\
41-60 \\
\text { Yrs }\end{array}$ & $434(42.3)$ & $283(27.6)$ & $47(4.6)$ & $8(0.8)$ & $352(42.6)$ & $244(29.5)$ & $34(4.1)$ & $2(.2)$ & 4.356 & 0.49 (NS) \\
\hline
\end{tabular}




\begin{tabular}{|c|c|c|c|c|c|c|c|c|c|c|c|}
\hline \multirow{3}{*}{ ঠ } & $>60 \mathrm{yrs}$ & $100(40.5)$ & $47(19.0)$ & $8(3.2)$ & $5(2.0)$ & $28(18.4)$ & $69(45.4)$ & $8(5.3)$ & $0(0)$ & 41.337 & $<0.001^{* *}$ \\
\hline & Male & $658(43.5)$ & $375(24.8)$ & $75(5.0)$ & $12(.8)$ & $516(42.0)$ & $235(19.1)$ & $34(2.8)$ & $5(.4)$ & 41.981 & $<0.001^{* *}$ \\
\hline & Female & $237(32.3)$ & $246(33.6)$ & $55(7.5)$ & $18(2.5)$ & $270(31.4)$ & $362(42.1)$ & $65(7.6)$ & $10(1.2)$ & 19.448 & $0.001^{*}$ \\
\hline & Punjab & $274(43.2)$ & $154(24.3)$ & $45(7.1)$ & $11(1.7)$ & $634(37.3)$ & $479(28.2)$ & $87(5.1)$ & $15(9)$ & 17.073 & $0.002^{*}$ \\
\hline עִ & $\begin{array}{l}\text { Out of } \\
\text { Punjab }\end{array}$ & $621(38.5)$ & $467(29)$ & $85(5.3)$ & $19(1.2)$ & 152(39.4) & $118(30.6)$ & $12(3.1)$ & $0(0)$ & 8.232 & $0.14(\mathrm{NS})$ \\
\hline
\end{tabular}

PHQ-9 Scale: Score 0 no Depression, 1-4: Minimal depression (Dep), 5-9: Mild depression (Mild Dep), 10-14: Moderate depression (Mod Dep), 15-19; Moderately severe depression (Mod severe Dep), 20-27: Sever depression.

P Value: ** Statistically highly significant $(p<0.001)$, *Statistically significant $(p<0.05)$, Statistically non- significant $(p>0.05)(N S)$

Response to the question about difficulties to do work, takes care of things at home, or get along with other people show that $57.9 \%$ (2510), 63.7\% (1431) and 51.7\% (1079) of the total study population, medico and nonmedicos respectively did not have any difficulty at all to do work, takes care of things at home, or get along with other people. Whereas somewhat difficulty was felt by $38.3 \%$ (1658), $32.4 \%$ (728) and $44.6 \%$ (930), much difficulty was felt by $3.0 \%(131), 3.1 \%(69)$ and $3.0 \%(62)$, extremely difficult was felt by $0.8 \%(34), 0.8 \%(18)$ and $0.8 \%(16)$ of total study population, medicos and nonmedicos respectively. The difference was observed to be statistically highly significant $\left(x^{2}=68.724 ; d f=3 ; p<0.001\right)$. Response to the question about the need for treatment among the total study population, medicos and nonmedicos showed that $69.9 \%$ (3030), 66.7\% (1497) and $73.5 \%$ (1533) of the total study population, medico and non-medicos respectively did not take any treatment for anxiety or depression. $27.2 \%$ (1177), 30.5\% (684) and $23.6 \%$ (493) of total study population, medico and nonmedicos respectively took occasional treatment, $2.9 \%$ (126), $2.9 \%$ (65) and $2.9 \%$ (61) of total study population, medico and non-medicos respectively took treatment regularly. The difference between medicos and nonmedicos was observed to be statistically highly significant. $\left(x^{2}=25.750 ; d f=2 ; p<0.001\right)$.

\section{DISCUSSION}

Historically, any disease pandemics are associated with serious psychological and mental health consequences. Evidence suggests mental health issues like stress, depression, anxiety, sleep disturbances, fear, anger and denial has escalated during the Covid-19 pandemic globally among general and vulnerable populations. ${ }^{[15]}$ Assessment of mental health issues is important for planning strategies to prevent and manage mental health issues.
We conducted, this survey to document the prevalence of anxiety and depression using GAD-7 and PHQ-9 scales respectively and found prevalence of anxiety in the study population was $80.5 \%$ including $79.3 \%$ medicos and $81.9 \%$ non-medicos whereas the prevalence of depression was $73.3 \%$ including $74.7 \%$ medicos and $71.7 \%$ non-medicos. There are paucities of studies from India exploring the prevalence of anxiety and depression during the COVID-19 pandemic making any comparison difficult, but the high prevalence of anxiety and depression in our study emphasizes the urgent need for strengthening the preventive, therapeutic and curative mental health care services in India. Depression and anxiety are the most common psychiatric disorders with a prevalence of $10 \%$ to $20 \%$ in the general population. ${ }^{[12]}$ In China, one of the first studies during COVID-19 among essential workers documented $20.1 \%$ prevalence of anxiety accessed by Beck Anxiety Inventory (BAI) and $12.7 \%$ prevalence of depressive symptoms accessed by Beck Depression Inventory-II (BDI-II) ${ }^{[16]}$, which is very low as compared to our study. Another study conducted in China showed moderate to severe anxiety symptoms in $28.8 \%$ and moderate to severe depressive symptoms in $16.5 \%$ of the respondents accessed by the Depression, Anxiety and Stress Scale (DASS-21). ${ }^{[17]}$

Among the general population, the prevalence of anxiety for found to be in the range of 2 to $37 \%$ in China, 7.2 to $11.5 \%$ in Italy, 1.2 to $4 \%$ in Spain and about $28 \%$ in India Whereas the prevalence of depression was reported to be in the range of 8.3 to $48.3 \%$ in China, 15.4 to $17 \%$ in Italy, $1.7 \%$ to $8.7 \%$ in Spain and about $25 \%$ in India accessed by using different tools for estimation of anxiety and depression, whereas we used GAD-7 and PHQ-9 scales. ${ }^{[13]}$ A meta-analysis found $23.2 \%$ pooled prevalence of anxiety and $22.8 \%$ depression accessed by different scales including GAD-7 and PHQ-9 scales. ${ }^{[18]}$ 
Another systematic review and meta-analysis involving 31 studies from South Asian countries reported 41.3\% pooled prevalence of anxiety during COVID-19 accessed using different assessment scales. Similarly, 28 studies using different assessment scales reported $34.1 \%$ pooled prevalence of depression during COVID-19. GAD-7 and PHQ-9 were the most frequently used assessment scales. ${ }^{[19]}$ Differences in the estimated overall prevalence of mental health disorders in various studies are thought to be because of different methodologies, population size, heterogeneity in study population and differences in diagnostic or screening criteria used. ${ }^{[20]}$ GAD-7 accessed higher prevalence of anxiety (49.2\%) compared to DASS-21 (34.2\%) and HADS (32.8\%) scales. Similarly, PHQ-9 accessed higher prevalence (34.7\%) of depression as compared to DASS-21 (29.8\%) and HADS (29.2\%) ${ }^{[19]}$ So the use of GAD-7 and PHQ-9 in our study may be the reason for very high prevalence of anxiety and depression. Studies from India and Singapore documented $15.7 \%$ and $10.6 \%$ prevalence of anxiety and depression among HCWs ${ }^{[21]}$ and $64.7 \%$ reported from Turkey both studies using the DASS-21 scale. ${ }^{[22]}$ Similarly, the study by Kazmi et al. ${ }^{[23]}$ documented the highest prevalence of anxiety and depression of $57 \%$ and $61.1 \%$ respectively using the DASS-21 scale. Prevalence of anxiety and depression in a web survey from Brazil and Spain was shown to be $8.3 \%$ and $11.6 \%$ for depression and anxiety respectively using GAD-7 and PHQ-9 scales. ${ }^{[20]}$ A cross-sectional study conducted in 359 South Indian medical students showed that $75.5 \%$ had anxiety symptoms accessed by GAD-7 scale and $74.6 \%$ had depression symptoms accessed by CES-D scale which were comparable to the results of our study. Another cross-sectional survey showed that $25.1 \%$ of the subjects were depressed and $28 \%$ were anxious over the last 3 weeks accessed by DASS-21 scale. ${ }^{[24]} \mathrm{A}$ meta-analysis documented $43.6 \%$ pooled prevalence of anxiety among $\mathrm{HCWs}$ and $40.7 \%$ among the general population, whereas the pooled prevalence of depression was (39\%) higher in the general population than (29.9\%) among HCWs. ${ }^{[19]}$ This also is less as compared to our study. Another meta-analysis showed $73 \%$ prevalence of anxiety among Egyptian medical students, 50.1\% prevalence of anxiety among Hong Kong nurses, 10.5\% prevalence of anxiety in the general American population, $20.9 \%$ prevalence of depression among physicians which is less as compared to the prevalence of anxiety and depression among medicos group in our survey. ${ }^{[12]}$ In our study, the prevalence of anxiety according to severity scales in medicos was $20.7 \%$ had no anxiety, $40.2 \%$ mild anxiety, 30.7\% moderate and $8.3 \%$ severe anxiety whereas in the non-medicos group $18.1 \%$ had no anxiety, $44.0 \%$ mild anxiety, $32.5 \%$ moderate and $5.4 \%$ severe anxiety. The results of our study were somewhat high as compared to the study showing $34 \%$ mild anxiety, $20 \%$ moderate anxiety and $14.8 \%$ moderately severe anxiety and $6.7 \%$ showed symptoms of severe anxiety using GAD-7 scales. ${ }^{[5]}$ Data analysis in our survey shows that in the medicos group, $25.3 \%$ had no depression, $39.8 \%$ had minimal depression, $27.6 \%$ mild depression, $5.8 \%$ moderate depression, $1.3 \%$ moderately severe depression and $0.0 \%$ suffered from severe depression whereas, among non-medicos group, $28.3 \%$ had no depression, $37.7 \%$ minimal depression, 28.6\% mild depression, $4.7 \%$ moderate depression, $0.7 \%$ moderately severe depression and $0.0 \%$ had severe depression. The results of our study were high as compared to a study showing $30.1 \%$ had mild depression, 20.3\% moderate depression, 15.3\% moderately severe depression and $8.9 \%$ had severe depression symptoms using CES-D scales. ${ }^{[25]}$ In our survey, according to gender, the prevalence of anxiety was $78.3 \%$ in males, $84.5 \%$ in females, including $78.1 \%$ in males and $81.6 \%$ in females among the medicos group, $78.4 \%$ in males and $87.3 \%$ in females among the nonmedicos group. Almost similar prevalence was observed in South Indian medical students' study where $73.5 \%$ males and $77.5 \%$ females showed the presence of anxiety symptoms using GAD-7 scales. ${ }^{[25]}$ In our study prevalence of anxiety according to the level of severity was $43.9 \%$ mild anxiety, $27.8 \%$ moderate anxiety and $6.5 \%$ severe anxiety in males and $32.7 \%$ mild anxiety, $36.8 \%$ moderate anxiety and $12 \%$ severe anxiety in females among the medicos group. Among the nonmedicos group, it was $55.5 \%$ mild anxiety, $19.7 \%$ moderate anxiety and $3.3 \%$ severe anxiety in males and $27.7 \%$ mild anxiety, 50.9\% moderate anxiety and $8.4 \%$ severe anxiety in females. Prevalence of anxiety according to the level of severity in South Indian medical students' study was observed to be mild anxiety $38.7 \%$ males and $29.2 \%$ females, moderate anxiety in $17.7 \%$ males and $22.5 \%$ females, moderately severe anxiety in $11.6 \%$ males and $17.9 \%$ females and severe anxiety was observed in $5.5 \%$ males and $7.9 \%$ female students using 
GAD-7 and CES-D scales. ${ }^{[25]}$ In our survey, the predominance of the prevalence of anxiety among females than males was observed, which was similar to the observation by the National mental health survey of India 2015-2016. ${ }^{[8]}$

Prevalence of depression related to gender observed in our study population was $69.7 \%$ in males, $79.3 \%$ in females and medicos group, the prevalence of depression was $74.1 \%$ in males and $75.9 \%$ in females whereas in the non-medicos group it was $64.3 \%$ in males and $82.3 \%$ in females. Prevalence of depression related to gender observed in South Indian medical students' study using CES-D scales ${ }^{[25]}$ was $72.9 \%$ in males and $76.4 \%$ in females with females showing more prevalence than males like in our study. In our study prevalence of depression according to the level of severity related to gender in medicos was observed to be minimal depression in $43.5 \%$ males, $32.3 \%$ females, mild depression in $24.8 \%$ males, $33.6 \%$ females, moderate depression in $5.0 \%$ males, $7.5 \%$ females, moderately severe depression in $0.8 \%$ males, $2.5 \%$ females and severe depression was observed in $0.1 \%$ males and $0.0 \%$ in females. Similarly in the non-medicos group minimal depression was observed in $42.0 \%$ males, $31.4 \%$ females, mild depression in $19.1 \%$ males, $42.1 \%$ females, moderate depression in $2.8 \%$ males, $7.6 \%$ females, moderately severe depression in $0.4 \%$ males, $1.2 \%$ females and severe depression was observed none of the males or females. Prevalence of depression according to the level of severity in South Indian medical students' study ${ }^{[25]}$ related to gender showed that $72.9 \%$ males and $76.4 \%$ females had depression, including mild depression in $31.5 \%$ males, $28.6 \%$ females, moderate depression in $18.8 \%$ males, $21.9 \%$ females, moderately severe depression in $15.4 \%$ males, $15.2 \%$ females and severe depression was observed in $7.2 \%$ males and $10.7 \%$ females. The similar predominance of females over males had been documented by the National mental health survey of India 2015-2016. ${ }^{[8]}$

There are paucities of studies comparing the prevalence of anxiety and depression based on region and our study observed $82.0 \%$ prevalence of anxiety in the Punjab group, $78.8 \%$ outside the Punjab group and the difference was statistically significant (0.008). The difference in the prevalence of anxiety in medicos and non-medicos according to the region was statistically not significant. Similarly, the prevalence of depression was observed to be $72.8 .0 \%$ in the Punjab group and $73.8 \%$ outside the Punjab group and the difference was statistically not significant (0.431), whereas the difference of prevalence of depression in medicos and non-medicos according to the region was statistically significant (0.018) in Punjab group and statistically not significant (0.703) outside Punjab groups.

Data analysis show that $57.9 \%$ of the total study population, $63.7 \%$ medico and $51.7 \%$ non-medicos did not have any difficulty at all to do work, whereas somewhat difficulty was felt by $38.3 \%$ of the total study population, $32.4 \%$ medico and $44.6 \%$ non-medicos, many difficulties were experienced by $3.0 \%$ of the total study population, $3.0 \%$ medico and $3.1 \%$ non-medicos and the extremely difficult situation was experienced by $0.8 \%$ of the total study population, $0.8 \%$ medico and $0.8 \%$ non-medicos. The difference observed was statistically highly significant $\left(x^{2}=68.724 ; d f=3 ; p<0.001\right)$. Data about the need for treatment by the study population showed that $69.9 \%$ of the total study population, $66.7 \%$ medicos and $73.5 \%$ non-medicos did not take any treatment for anxiety or depression, whereas $27.2 \%$ of the total study population, $30.5 \%$ medicos and $23.6 \%$ of non-medicos took occasional treatment and only $2.9 \%$ of the total study population, $2.9 \%$ medicos and $2.9 \%$ non-medicos took treatment regularly. The difference between medicos and nonmedicos was observed to be statistically highly significant. $\left(x^{2}=25.750 ; d f=2 ; p<0.001\right)$.

Results of our study, necessitate initiation of measures to curb, decrease and minimize the increasing prevalence of mental health disorders and psychiatric morbidity during Covid-19 pandemic like psychological interventions, supports for high-risk population, education for identification of mental health issues, awareness of psychiatric symptoms, curbing media exposure, break from work, increased peer support and easy access to psychiatric help through different methods of social media and telemedicine will help in reducing the psychological and psychiatric morbidity. ${ }^{[26]}$ In India mental health scenario in the pre-COVID-19 era was grim with psychiatric issues becoming more complicated during the COVID-19 pandemic because of the high prevalence of pre-existing mental disorders, deficient mental health care infrastructure and help, huge deprived population, uncontrolled information and misinformation on social, electronic and print media. ${ }^{[27]}$ 
Keeping in mind, India specific COVID and mental health conditions, Government of India (GOI)-MOHFW issued Psycho-Social toll-free helpline-08046110007 and web portal providing access to stress coping strategies, advice, videos, meditation and yoga practices to help people especially the vulnerable section of society to take care of their mental health issues.

Very high prevalence of anxiety and depression documented by our study also justify the NIMHANS suggestion to form a 'Psychological intervention medical team' competent to formulate mental health interventions strategies to address mental health issues during the COVID-19 pandemic. ${ }^{[28]}$ Results of our survey suggest initiation of urgent measures to address mental health issues and their psychological impacts to contain and curb grave adverse effects of mental disorders including anxiety and depression.

\section{CONCLUSIONS}

Results of our survey suggest a high prevalence of anxiety and depression in the Indian population. More people were found to be suffering from mild anxiety and mild depression during the COVID-19 pandemic. Sociodemographic variables like age groups, gender, region and job status influenced the prevalence of anxiety and depression in the study population as well as among medico and non-medico groups. Results of our survey may be helpful for the policymakers and the government to initiate and device diagnostic, preventive and management strategies to address the psychological as well as psychiatric needs of the Indian population.

Because, the Mental Healthcare Act, 2017 guaranteed the right to mental health care for the Indian population, the findings of this survey will help identify mental health care needs during these challenging times of the COVID19 pandemic to initiate appropriate measures to promote the mental well-being of our population with initiating infrastructure strengthening and recruiting sufficient mental health care professionals.

\section{CONTRIBUTION OF AUTHORS}

Research concept- Meghna Gupta, Vitull K Gupta, Navjot Kaur

Research design- Meghna Gupta, Vitull K Gupta, Navjot Kaur

Supervision- Meghna Gupta, Vitull K Gupta, Navjot Kaur Materials- Meghna Gupta, Vitull K Gupta, Navjot Kaur, Parneet K. Hari, Kashish Goyal
Data collection- Meghna Gupta, Vitull K Gupta, Navjot Kaur, Parneet K. Hari, Kashish Goyal

Data analysis and Interpretation- Meghna Gupta, Vitull K Gupta, Navjot Kaur, Parneet K. Hari, Kashish Goyal

Literature search- Meghna Gupta, Vitull K Gupta, Navjot Kaur, Parneet K. Hari, Kashish Goyal

Writing article- Meghna Gupta, Vitull K Gupta, Navjot Kaur, Parneet K. Hari, Kashish Goyal

Critical review- Meghna Gupta, Vitull K Gupta, Navjot Kaur

Article editing- Meghna Gupta, Vitull K Gupta, Navjot Kaur, Parneet K. Hari, Kashish Goyal

Final approval- Meghna Gupta, Vitull K Gupta, Navjot Kaur, Parneet K. Hari, Kashish Goyal

\section{REFERENCES}

[1] Zhou P, Yang XL, Wang XG, Hu B, Zhang L, et al. A pneumonia outbreak associated with a new coronavirus of probable bat origin. Nature, 2020; 579(7798): 270-73.

[2] Chan JFW, Yuan S, Kok KH, To KKW, Chu H, et al. A familial cluster of pneumonia associated with the 2019 novel coronavirus indicating person-to-person transmission: a study of a family cluster. Lancet, 2020: 395(10223): 514-23.

[3] Cucinotta D, Vanelli M. WHO Declares COVID-19 a Pandemic. Acta Biomed., 2020: 91(1): 157-60.

[4] Leigh-Hunt N, Bagguley D, Bash K, Turner V, Turnbull $S$, et al. An overview of systematic reviews on the public health consequences of social isolation and loneliness. Public health, 2017: 152, 157-71.

[5] Dubey S, Biswas P, Ghosh R, Chatterjee S, Dubey MJ, et al. Psychosocial impact of COVID-19. Diabetes \& Metabolic Syndrome: Clin Res Rev., 2020: 14 (5): 779-88.

[6] Amsalem D, Dixon LB, Neria Y. The Coronavirus Disease 2019 (COVID-19) Outbreak and Mental Health: Current Risks and Recommended Actions. JAMA Psychiatry, 2021; 78(1): 9-10.

[7] Taylor S. The Psychology of Pandemics: Preparing for the Next Global Outbreak of Infectious Disease. Newcastle upon Tyne, Cambridge Scholars Publishing, 2019.

[8] Gururaj G, Varghese M, Benegal V, Rao GN, Pathak K, et al. National Mental Health Survey of India, 201516: Prevalence, patterns and outcomes. Bengaluru, National Institute of Mental Health and Neuro Sciences, NIMHANS Publication No. 129, 2016. 
[9] Spitzer RL, Kroenke K, Williams JB, Löwe B. A brief measure for assessing generalized anxiety disorder: the GAD-7. Arch Intern Med., 2006; 166(10): 109297.

[10]Kroenke K, Spitzer RL. The PHQ-9: A new depression diagnostic and severity measure. Psychiatry Ann., 2002; 32(9): 509-15.

[11]Kumar RP. COVID-19 and mental health: A review of the existing literature. Asian J Psychiatry, 2020; 52: 102066.

[12]Salari N, Khazaie $H$, Hosseinian-Far A, et al. The prevalence of stress, anxiety and depression within front-line healthcare workers caring for COVID-19 patients: a systematic review and metaregression. Hum Resour Health, 2020; 18: 100.

[13]Ram L, Amit A, Manoj S. Prevalence of Depression, Anxiety, and Stress during COVID-19 Pandemic. J Neurosci Rural Pract., 2020; 11(4): 519-25.

[14]Elezi F, Tafani G, Sotiri E, Agaj H, Kola K. Assessment of anxiety and depression symptoms in the Albanian general population during the outbreak of COVID-19 pandemic. Indian J Psychiatry, 2020; 62: 470-75.

[15] Torales J, O' Higgins M, Castaldelli-Maia JM, Ventriglio A. The outbreak of COVID-19 coronavirus and its impact on global mental health. Int J Soc Psychiatry, 2020; 66(4): 317-20.

[16]Du J, Dong L, Wang T, et al. Psychological symptoms among frontline healthcare workers during COVID-19 outbreak in Wuhan. General Hospital Psychiatry, 2020; 67: 144-45.

[17]Wang C, Pan R, Wan X, Tan Y, Xu L, et al. Immediate psychological responses and associated factors during the initial stage of the 2019 coronavirus disease (COVID-19) epidemic among the general population in China. Int J Environ Res Public Health 2020; 17: 1729.

[18]Pappa S, Ntella V, Giannakas T, Giannakoulis VG, Papoutsi E, et al. Prevalence of depression, anxiety, and insomnia among healthcare workers during the COVID-19 pandemic: A systematic review and metaanalysis. Brain Behav Immun., 2020; 88: 901-07.
[19]Hossain MM, Rahman M, Trisha NF, et al. Prevalence of anxiety and depression in South Asia during COVID-19: A systematic review and metaanalysis. Heliyon. 2021; 7(4): e06677.

[20]De Boni RB, Balanzá-Martínez V, Mota JC, Cardoso TDA, Ballester $P$, et al. Depression, Anxiety, and Lifestyle Among Essential Workers: A Web Survey From Brazil and Spain During the COVID-19 Pandemic. J Med Internet Res., 2020; 22(10): e22835.

[21]Chew NW, Lee GK, Tan BY, Jing M, Goh Y, et al. A multinational, multicentre study on the psychological outcomes and associated physical symptoms amongst healthcare workers during COVID-19 outbreak. Brain Behav Immun., 2020; 88: 559-65.

[22] Elbay RY, Kurtulmuş A, Arpacıoğlu S, Karadere E. Depression, anxiety, stress levels of physicians and associated factors in Covid-19 pandemics. Psychiatry Res., 2020; 290: 113130.

[23]Kazmi SSH, and Hasan K, Talib S, Saxena S. COVID-19 and Lockdown: A Study on the Impact on Mental Health. Mukt Shabd J., 2020: 9(4): 1477-89.

[24]Shankey V, Aditi M. Depression, anxiety, and stress and sociodemographic correlates among general Indian public during COVID-19. Int J Soc Psychiatry, 2020: 66(8): 756-62.

[25]Nihmath NS, Francis YM, Balaji K, Raghunath G, Kumaresan M. A survey on anxiety and depression level among South Indian medical students during the COVID 19 pandemic. Int J Res Pharm Sci., 2020: 11(1): 779-86.

[26] Ho CS, Chee CY, Ho RC. Mental health strategies to combat the psychological impact of COVID-19: beyond paranoia and panic. Ann Acad Med Singapore, 2020; 49: 1-3.

[27]Roy A, Singh AK, Mishra S, Chinnadurai A, Mitra A, et al. Mental health implications of COVID-19 pandemic and its response in India. Int J Soc Psychiatry, 2021; 67(5): 587-600.

[28]Cullen W, Gulati G, Kelly BD. (2020). Mental health in the COVID-19 pandemic. QJM: Monthly J Association Physicians, 113(5), 311-12. 